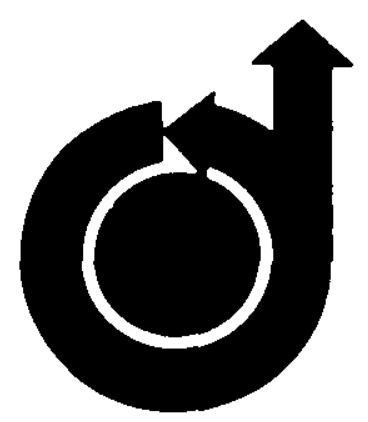

78-3

\title{
The Effect of Ambient Conditions on the Emissions of an Idling Gas Turbine
}

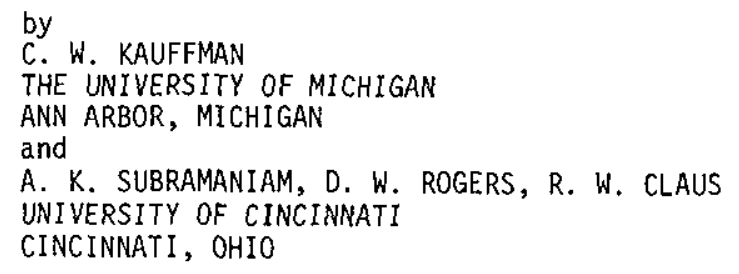

\section{AIAA 16TH AEROSPACE SCIENCES MEETING}

Huntsville, Alabama/January 16-18, 1978 


\author{
C.W. Kauffman $* *$ \\ The University of Michigan \\ Ann Arbor, Michigan 48109 \\ A.K. Subramaniam, D.W. Rogers, R.W. Claus ${ }^{\dagger}$ \\ University of Cincinnati \\ Cincinnati, Ohio 45221
}

\section{Abstract}

Changes in ambient conditions--pressure, temperature, and humidity - affect the exhaust emissions of a gas turbine engine. Such variations must be compensated for during engine certification. The results of a test program employing a JT8D-17 combustor are presented which quantize the effect of carefully controlled changes on unburned hydrocarbons, carbon monoxide, and oxides of nitrogen at simulated idle operating conditions. Analytical results are given to explain the observed hydrocarbon and carbon monoxide behavior. It is shown that for a complete range of possible ambient variations, signiflcant changes do occur in the amount of pollutants emitted by an idling gas turbine.

\section{Introduction}

Environmental Protection Agency regulations pertaining to emission standards for gas turbine engines specify maximum quantities of the pollutant species which may be exhausted during a landing and take-off cycle for engine inlet conditions corresponding to those of a standard day. However, only occasiona1ly are ambient conditions those of a standard day and it is necessary to develop correction techniques in order to be able to relate emission measurements as actually made from an engine or combustor to those which would have occurred on a standard day.

The effect of inlet pressure, temperature, and humidity on the oxides of nitrogen produced by an engine when operating at take-off power settings was noted quite early by Lipfert 1 , and subsequently numerous correction factors were formulated. A compilation and evaluation of these has been recently given by Rubins and Marchionna ${ }^{2}$. For a combustor operating at idle conditions additional corrections were developed by Marzeski and Blazowski ${ }^{3}$ to account for the effects of nonstandard inlet pressure and temperature on all emissions. For production samples of a given engine the effect of ambient temperature and pressure on all emissions over the complete thrust range has been correlated by Sarli et al.4. With the exception of some lim-ited engine test results given by Nelson et al. 5 and Mosier and Roberts 6 and the work reported by Allen and Slusher ${ }^{7}$ the effect of humidity on idle emissions apparently has received little attention although the extreme sensitivity of $\mathrm{CO}$ oxidation to the presence of water vapor is well known.

*This work was supported under NASA Grant NSG 3045, NASA Lewis Research Center, Airbreathing Engines Division, Robert E. Jones, Contract Monitor.

**Associate Research Scientist, Department of Aerospace Engineering.

tstudents, Department of Aerospace Engineering and Applied Mechanics.
In order to ascertain the effect of ambient relative humidity on gas turbine idle emissions a research effort was initiated encompassing both experimental and analytical work. Results generated during the program are reported in this paper. Experimentally a nonvitiating combustor rig was employed to simulate changing combustor inlet conditions as generated by changing ambient condition. Emissions measurements were made at the combustor exit. Analytically for the carbon monoxide a kinetic reaction scheme was applied within each zone of the combustor where temperatures and initial species concentrations not only reflected local combustor characteristics but also changing ambient conditions, while for the hydrocarbon emissions the vaporization of fuel drops passing through temperature profiles determined by local combustor conditions and changing ambient conditions was examined.

\section{Experimental Program}

\section{Test Apparatus}

The experimental program was conducted in a closed duct test facility, described in detail by Fear ${ }^{8}$, located in the Engine Research Building of the NASA Lewis Research Center. A single JT8D-17 combustor can, shown in cross section in Fig. 1 , was supplied with the appropriate quantity of Jet A fuel and nonvitiated air to simulate combustor inlet conditions corresponding to specified engine inlet pressure, temperature, and humidity. The combustor installation and instrumentation are shown in Fig. 2. The water content of the inlet air was controlled by injecting demineralized water through a spray nozzle into the hot air supplied by the preheater approximately 5 meters upstream of the combustor thereby assuring complete vaporization. The water content of the air supplied by the preheater was continually monitored and nominally quite small (dew point of approximately $239 \mathrm{~K}$ ). The combustor emlssions were measured according to SAE specifications ${ }^{9}$.

\section{Test Conditions}

The idle operating conditions, both nominal and as tested, are given in Table $I$. In relating the amblent variables to combustor inlet variables, compressor pressure ratios of 2 to 5 were chosen along with a compressor efficlency of $80 \%$. The mass flow through the combustor was calculated on the basis of a constant compressor discharge Mach number or a constant reference velocity. Since the mass flow into the combustor consists of both air and water, the combination of which may be considered as an oxidizer, the fuel flow was set to maintain a constant fuel/air ratio and not a constant fuel/oxidizer ratio. Because the combustor was of fixed geometry three different values of the overall fuel/air ratio were run in order to affect local fuel/air ratios within the combustor. 


\section{Experimental Results}

Representative values of the measured emissions from the JT8D-17 combustor are given in Figs. 3-6 in terms of the emission index, EI = gms of pollutant $/ \mathrm{kg}$ of fuel. All figures correspond to one simulated compressor discharge condition - a pressure ratio of four and a constant Mach number. On each figure three sets of data are given-one for each overall fuel/air ratio. For al1 other conditions remaining constant a larger fuel/air ratio gives a higher combustor discharge temperature, $\tilde{r}_{4}$. Within each of the three fuel/air ratio groupings two parameters are independently varied - the ambient temperature, $\mathrm{T}_{\mathrm{O}}$, and the relative humidity, $\mathrm{RH}$. For each of the three ambient temperatures considered data points are presented for three relative humidities with the exception of $\mathrm{T}_{\mathrm{O}}=244 \mathrm{~K}$ where an extremely small quantity of water corresponds to saturation and only one value of relative humidity is given. For a fixed fuel/air ratio and zero relative humidity increasing ambient temperature increases the combustor discharge temperature while for a fixed fuel/air ratio and ambient temperature increasing the relative humidity decreases the combustor discharge temperature.

For the first two figures the following trends are recognized. For a fixed set of ambient conditions an Increase in the fuel/air ratio leads to a decrease in the hydrocarbon and carbon monoxide emission index. For a fixed fuel/air ratio and zero humidity an increase in the ambient temperature causes a decrease in the emission index. For a fixed fuel/air ratio and a given ambient temperature an increase in the relative humidity causes an increase in the emission index, an effect which is especially noticeable at the highest ambient temperature where saturation corresponds to the presence of $8.12 \%$ of mass water vapor.

For regulatory purposes the combustor discharge temperature, $\mathrm{T} 4$, is not a convenient parameter, but it was thought that its use would provide insight with regard to the processes occurring within the combustor. For the hydrocarbons and carbon monoxide $T_{4}$ does not uniquely determine the emissions. Fue1/air ratio, ambient air temperature, and ambient air humidity are all important. For all fuel/air ratios the slope, $\left[\partial(E I-H C) / \partial T_{4}\right]_{R H}=0.0$, is less negative than the slope, $\left[\partial(\mathrm{EI}-\mathrm{HC}) / \partial \mathrm{T}_{4}\right]_{\mathrm{RH}}=1.0$, with both becoming less negative with increasing fuel/air ratios. For all fuel/air ratios the slope, $\left[\partial(\mathrm{EI}-\mathrm{CO}) / \partial \mathrm{T}_{4}\right]_{\mathrm{RH}}=0,0$, is nearly identical while the slope, [ $\left[\partial(\mathrm{EI}-\mathrm{CO}) / \partial \mathrm{T}_{4}\right]_{\mathrm{RH}}=1.0$, increases with decreasing fuel/air ratio. At the highest fuel/air ratio the two slopes are nearly identical.

For the third figure the following well known trends are evident. For a fixed set of ambient conditions an increase in the fuel/air ratio leads to an increase in the oxides of nitrogen emission index except at the highest absolute humidity conditions $\left(\mathrm{T}_{\mathrm{O}}=322 \mathrm{~K}, \mathrm{RH}=100 \%\right.$ ). For a fixed fuel/air ratio and zero humidity an increase in the ambient temperature causes an increase in the emission index. For a fixed fuel/air ratio and a given ambient temperature an increase in the relative humidity causes a decrease in the emission index, again an effect which is quite noticeable when the quantities of water vapor are large. For a given $\mathrm{T}_{4}$ a wide variation in the emisison index is obvious. The slopes, $\left[\partial\left(\mathrm{EI}-\mathrm{NO}_{\mathrm{X}}\right) / \partial \mathrm{T}_{4}\right]_{\mathrm{RH}}=0.0$ and

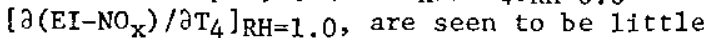

affected by the value of the fuel/air ratio, and the former has a slightly smaller value than the latter. The combustion efficiency for each point is also indicated, and for similar values there may be large differences in the emission index.

In the last of this group of figures the nitrogen dioxide emission index for the smallest value of the fuel/air ratio shows trends identical to those discussed above for the total oxides of nitrogen. It is difficult to recognize a functional dependence of the emission index on ambient conditions for the higher values of the fuel/air ratio. Consideration of data collected at other simulated idle operating conditions will delineate this problem further.

In these figures only a limited amount of the emission data collected is presented, i.e. a compressor pressure ratio of four and a constant compressor discharge Mach number. A comparison of all emission data shows that for a given pressure ratio 1ittle difference exists between the emission levels and trends for the case of a constant reference velocity as compared to the case of a constant compressor discharge Mach number. However, an increase in the pressure ratio does cause a decrease in hydrocarbon and carbon monoxide emission indices and an increase in the oxides of nitrogen and nitrogen dioxide emission indices. An examination of this additional data shows that the functional dependence of the nitrogen dioxide emission index is identical to that of the total oxides of nitrogen emission index as Iong as the combustor discharge temperature is less than approximately $900 \mathrm{~K}$. Above this temperature the expected quantities of nitrogen dioxide do not appear. For all data, the range in ambient conditions considered certainly produce large variations in the emission indices.

Other combustor emission data is surprisingly similar to that collected for the JT8D-17. The emission data of Marzeski and Blazowski ${ }^{3}$ was collected using a T-56 combustor employing two different fuels and differing primary zone fuel/air ratios for a constant overall fuel/air ratio. The relative humidity of the inlet air was close to zero. A1though the absolute values of the emission indices vary slightly for identical compressor ratios the

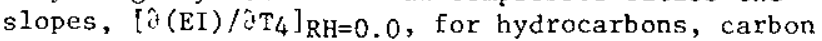
monoxide, and oxides of nitrogen are nearly identical. A similarity among combustors would ease the regulatory task of developing corrections for nonstandard inlet conditions.

\section{Correlation Factors}

For regulatory purposes the convenient independent variables in a correlation equation are those at the compressor discharge plane- $-\mathrm{p}_{3}, \mathrm{~T}_{3}$, and humidity (HUM) - in addition to the fuel/aix ratio (FAR). The data collected in this study was employed to generate such an equation for the emission index of each pollutant species (EI). Because of the similarity between the constant velocity and constant Mach number data separate correlations were not developed. The emission data was fit employing a stepwise multiple linear regression program to determine the coefficients in an equation of the following form:

$$
\mathrm{EI}=\mathrm{p}_{3}{ }^{\mathrm{a}} \exp \left[\mathrm{b}+\frac{\mathrm{FAR}}{\mathrm{c}}+\frac{\mathrm{T}_{3}}{\mathrm{~d}}+\frac{\mathrm{HUM}}{\mathrm{e}}\right],
$$

where the respective dimensions are: $\operatorname{EI~}(1 \mathrm{bm} / 103$ $1 \mathrm{bm}), \mathrm{p} 3$ (psia), $\mathrm{T}_{3}\left({ }^{\circ} \mathrm{R}\right)$, and HUM ( $1 \mathrm{bm}$ water $/ 10^{3} 1 \mathrm{bm}$ 
air). The coefficients as determined by the program are given in Table II for two extremes - all data collected and various subcases selected to maximize correlation. In the latter case for the hydrocarbons (HC) and the carbon monoxide ( $\mathrm{CO}$ ) the data collected at a compressor discharge pressuxe of 2 atmospheres was not included in that combustion is most marginal under these clrcumstances and for the case of oxides of nitrogen $\left(\mathrm{NO}_{\mathrm{x}}\right)$ only the data for a fuel/air ratio of 0.015 was included in that production of oxides of nitrogen is highest under these conditions. Graphically the agreement between the measured emission data and that predicted by the regression analysis in the case of the selected data is shown in Figs. 7-9. The relationship between the emissions and the ambient variables would appear to be adequately established.

\section{Analytical Effort}

\section{Mode1}

The experimental results indicate that the HC and $C O$ emissions are decreased by an increasing fuel/air ratio, pressure ratio, and ambient temperature, while they are increased by an increasing ambient humidity. For the $\mathrm{NO}_{\mathrm{x}}$ emissions the situation is just the reverse. The behavior of the $\mathrm{NO}_{\mathbf{x}}$ enissions have been modelled to account for all effects l1. Some details of the modelling process relevant to the production of carbon monoxide in the gas turbine combustor have been previously given by Morr et al.12 and a less detailed model but Including limited ambient affects has been presented by Sarli ${ }^{4}$. In attempting to define a tractable but yet accurate mode1 of the combustion process occurring within a gas turbine combustor conflicts will arise. In the model considered here it is suggested that the combustor may be treated as a plug flow reactor in which there is homogeneous reaction between the perfectly mixed fuel and oxidizer under isothermal conditions corresponding to the adiabatic flame temperature. Additionally, since the kinetics representing the oxidation of a complex hydrocarbon fuel, such as Jet $A$, are only poorly understood methane is chosen as the fuel for employment in the analytical effort. It is relevant to observe, however, that at the termination of the primary zone species composition closely approxinating equilibrium is achieved. Previous hydrocarbon emission modelifing conducted by Marchionna et al.13 indicates that much of the emissions result from the escape of raw fuel. Hence here it is necessary to consider the vaporization of fuel droplets as they pass in a plug flow fashion through the combustor.

The combustor inlet conditions corresponding to the temperature, pressure, and water content of the compressor discharge mass flow are identical to those in the experimental measurements. In the situation for the modelling of the carbon monoxide the methane is instantaneously mixed with the air and water vapor mixture in the primary zone to obtain the desfred equivalence ratio. The mixture is then allowed to react for a perlod of time corresponding to an appropriate primaxy zone residence time at a temperature which corresponds to the adiabatic flame temperature. The primary zone combustion products are then instantaneously mixed again with a quantity of additional air to simulate entrance Into the secondary combustion zone. The mixture is again allowed to react at a temperature representing the new adiabatic flame temperature for a period of time representing an appropriate residence tine. This process is again repeated in the dilution zone. With respect to the hydrocarbons a size distribution of JP-4 droplets is passed in a plug flow fashion through the respective zones of the combustor where the amount of vaporization is determined by the local adiabatic flame temperature and the local residence time.

For both pollutant species the calculation process is initiated by determining the adiabatic flame temperature for each simulated compressor discharge condition and a variety of fuel/air ratios using the NASA CEC-71 Computer Program 14. Each fuel/air ratio of course could correspond to a different location within the combustor where the local value is indeed affected by the overall fuel/air ratio. In the case of the carbon monoxide the methane/air kinetic scheme employed is that given by Ay and Siche115, Iisted in Table III. The second rate constant is similar in nature to that developed by Kollrack16, and it is found that the analytical model is much more successful in reproducing the magnitude of the experimental results when thts smaller value is used. It may be worthwile to note that the species $\mathrm{HO}_{2}$ and $\mathrm{NO}_{2}$ are not included in the reaction scheme. Simultaneous solution of the rate equation for each species is obtained using the NASA GCKP-72 Computer Program 17. The inttial spectes composition utilized in this program differs for each ambient condition and for each combustor region. The integration routine is carried out for a period corresponding to the residence time for each combustor region. Representative fuel/atr ratios and residence times employed for the regions within the combustor are given in Table IV. In the case of the hydrocarbons limited atomization data exists for the JT8D-17 fuel nozzle. A Rosin-Rammler droplet size distribution function was assumed which gives the weight fraction of particles, $R$, having a diameter larger than a given diameter, $x$,

$$
R=\exp \left[\begin{array}{lll}
-b & \times
\end{array}\right]
$$

The value of the parameter indicating the nonmonodisperse nature of the spray, $q$, was assumed to be similar to those determined for airblast atomizers 13 . The value of the parameter relating to the mean size, b, was obtained by fitting experimentally measured emission data for a reference case. To calculate the amount of fuel evaporating the drop distribution was divided into small segments and the usual diameter squared vaporization law was applied including corrections for convective enhancement of the vaporization as given by $\left(1+.276 \mathrm{Re} \cdot{ }^{\mathrm{Pr}} \cdot 33\right)$. The Reynolds number, Re, and the Prandt1 number, $\mathrm{Pr}$, as well as othet pertinent vaporization parameters wore determined by the local conditions in each zon: of the combustor where the droplets were allowed to reine $i$ : for the appropriate residence time.

\section{Analytical Results}

All results presented here are for a compressor pressure ratio of four.

Values of the adiabatic flame temperature reflecting the effects of ambient condittons are given in F1g. 10. The well known effect of humidity on the flame temperature is clear. At a given fuel/air ratio the effect of humidity on the equivalence ratio may also be signiftcant as shown in Fig. I1.

The effect of ambient conditions on the amount of $\mathrm{CO}$ at the end of the primary zone is shown in a 
normalized fashion in Fig. 12 for a primary zone residence time of one millisecond. Here $C_{F_{C O}}$ is defined as the mole fraction of carbon monoxide at standard ambient conditions $\left(\mathrm{T}_{\mathrm{O}}=289, \mathrm{RH}=0 \%\right)$ divided by the mole fraction of carbon monoxide at nonstandard ambient conditions. Three different primary zone equivalence ratios are considered, but the effects of ambient temperature and humidity changes are the same for each. An increase in the ambient temperature causes an increase in the carbon monoxide mole fraction and an Increase in the ambient humidity causes a decrease in the carbon monoxide mole fraction. These effects are precisely opposite to that observed for the gas turbine but agrees well with the flame results of MullerDethlefs and Schlader ${ }^{18}$. These results may be simply explained by considering the effect of flame temperature on dissociation. The species present at the end of the primary zone closely correspond to those which would be present for the case of chemical equilibrium. Miles 19 also finds the same inverse ambient effects when the primary zone is treated as a perfectly stirred reactor employing a global hydrocarbon kinetic scheme.

In view of the above results changing ambient conditions must indeed have an effect on the kinetics in the secondary and dilution zones. The mole Eraction of carbon monoxide, $\mathrm{X}_{\mathrm{CO}}$, exiting the combustor is given in Figs. 13, 14 and 15. On each figure one prinary zone fuel/air ratio is considered and this is diluted to lower fuel/air ratios in the secondary and dilution zones. Differing sequences are denoted by the differently shaded symbols in the figures and for each sequence changes in both the ambient temperature and ambient humidity are considered. The residence time for each of the three combustor regions is individually taken as five milliseconds.

The importance of the secondary zone on carbon monoxide emissions is illustrated in Fig. 13 where the products of combustion from a primary zone having a fuel/air ratio of 0.070 are exhausted at a dilution zone fuel/air ratio of 0.015 . The largest levels of carbon monoxide emission occur for the smallest values of the secondary zone fuel/air ratio, $i . e$, the carbon monoxide oxidation reaction is quenched. Examining the results for any one of the secondary zone fuel/air ratios, the effect of changing ambient conditions on the carbon monoxide is evident. For zero ambient humidity an increase in the ambient temperature decreases the emisstons while for a given ambient temperature an increase in the ambient humidity increases the emissions. The slopes, $\left[\partial \mathrm{x}_{\mathrm{CO}} / \partial \mathrm{T}_{4}\right]_{\mathrm{RH}}=0.0$ and $\left[\partial \mathrm{x}_{\mathrm{CO}} / \partial \mathrm{T}_{4}\right]_{\mathrm{RH}=1.0}$, are seen to depend upon the fuel/air ratio of the secondary zone.

In an actual combustor, however, each secondary zone will have a unfque, corresponding dilution zone. In Fig. 14 leaner secondary zones are paired with leaner dilution zones. Not surprisingly the least carbon monoxide is produced by the sequence with the richest secondary and dilution zones. The effect of differing ambient temperature and humidity is the same as discussed with regard to the previous figure. The slopes $\left[\partial \mathrm{X}_{\mathrm{CO}} / \partial \mathrm{T}_{4}\right]_{\mathrm{RH}}=0.0$ and $\left[\partial \mathrm{X}_{\mathrm{CO}} / \partial \mathrm{T}_{4}\right]_{\mathrm{rh}=1.0}$ differ from each other and depend upon the dilution sequence.

For a fixed geometry combustor operating at constant reference velocity or constant inlet Mach number an increase in the primary zone fuel/a1r ratio will also increase the secondary and dilution fuel/air ratios. This situation is illustrated by the flow sequences in Fig. 15. Here again the secondary and dilution zones are paired, the effect of changing ambient conditions is again obvious but comparing leaner and richer primary zones the slopes, $\left[\partial \mathrm{X}_{\mathrm{CO}} / \partial \mathrm{T}_{4}\right]_{\mathrm{RH}}=0.0$ and $\left[\partial \mathrm{X}_{\mathrm{CO}} / \partial \mathrm{T}_{4}\right]_{\mathrm{RH}}=1.0$, are quite similar for the lower values of $\mathrm{T}_{4}$ and the former only slightly more negative than the latter for higher values of $\mathrm{T}_{4}$.

$\Lambda$ comparison between the last two flow sequences in Fig. 14 and the first two flow sequences in Fig. 15, thereby eliminating the possibility of creating a rich dilution zone from a lean primary zone and vice versa, shows that the richer primary and subsequent zones give lower carbon monoxide emissions.

For lean idle operating conditions corresponding to a combustor exit fuel/air ratio of 0.007 a slight modification of the modelling scheme became necessary. Consideration of only three combustor zones as above produced very little carbon monoxide at the combustor exit plane. An analysis of this problem indicated that too small of a quantity was being produced in the lean primary zone-equivalence ratios varying between 0.45 and 0.65 . In a lean actual combustor with a fuel spray, combustion. will occur at approximately stoichiometric in the droplet diffusion flame and these products of combustion will then be further diluted by the excess air present. A similar approach was employed in the current homogeneous combustion mode1. The methane and oxidizer were allowed to react stoichiometrically for a short period of time$.5 \mathrm{~ms}-$ chosen so as to produce large amounts of carbon monoxide and then an Initial dilution was allowed to occur within the primary zone to some lower equivalence ratio where reactions were allowed to continue for the usual 5 ms. These products were then exhausted into the usual secondary and dilution zones. The results of such a calculation are shown in Fig. 16 and the usual ambient effects may be recognized.

For the hydrocarbon emissions, calculations were performed at one overall fuel/air ratio of 0.011 . The effect of three different ambient condttions on the fraction of a drop evaporated at the combustor exit plane for different diameter drops is presented in Fig. 17. Because of the effect on flame temperature cold and wet ambient air is effective in supressing vaporization. Through a combination of those results and the previously discussed droplet distribution function the total quantity of hydrocarbon emission may be calculated and the results are presented in Table V. For both the static and convective vaporization case, emtsslons are increased with respect to the base leve1 $322 \mathrm{~K}, 0 \% \mathrm{RH}$ - though either cooling of the amblent atr or through an increase in the humidity of the ambient air. The emissions are more sensitive to wide humidity variations than wide temperature changes.

\section{Experimental and Analytical Comparisons}

Both collected and calculated results show that for zero ambient relative humidity an increasing ambient temperature decreases hydrocarbon and carbon monoxide emissions and that for a given ambient temperature an increasing ambient relative humidity increases hydrocarbon and carbon monoxide emissions. 
Analytically for the carbon monoxide the latter effect could only be obtained employing the modiffed $\mathrm{CO} / \mathrm{OH}$ rate constant. A direct comparison is given In Figs. 18 to 20 where the emissions at. standard conditions are divided by those at nonstandard conditions and plotted as a function of ambient temperature with relative humidity as a parameter. The agreement in the magnitude of the emission changes is reasonable, however the kinetic calculations are unable to predict a sufficiently large increase in the carbon monoxide emisstons with increasing humidity. At present the reason for this disagreement is not known, but any comparison is affected by the path chosen in the kinetic model by which the primary zone combustion products are diluted down to the exit conditions. As already Indicated by Morx et al.13, a Gaussian distribution should be considered for the local restdence times as well as for the local fuel/atr ratios. For the hydrocarbon emissions as given in Table $V$, the predicted effect of changing ambient conditions is much less severe than those actually observed. However, this disagreement is believed in part due to the changing character of the fuel spray as ambient conditions vary. In that the data was run at a constant fuel/air ratlo as water replaced air with increasing humidty, it was necnecessary to decrease the fuel flow which caused poorer fuel atomization. At run conditions for a pressure ratio of two, the entire combustor fuel flow is supplied only by the primary portion of the duplex fuel nozzle. The Sauter mean diameter, SMD, of the spray is directly proportional to the fuel mass flow and inversely proportional to the nozzle pressure drop. Calculated SMD's are superimposed upon the emission data in Fig. 21 where for a given combustor discharge temperature the highest values of emission are seen to correspond to the largest value of the SMD.

\section{CONCLUSIONS}

Changing ambient conditions are observed and predicted to significantly affect idle emissions from a gas turbine engine. The combustor discharge temperature or adlabatic flame temperature does not uniquely determine the emissions thereby allowing a mechanism for the normalization of emissions under differing ambient conditions, however. changes may be calculated employing compressor discharge parameters. Fuel/air ratio changes which may result from engine control systems reacting to changing amblent conditions while attempting to maintain a constant $T_{4}$ may slgnificantly affect emissions.

\section{ACKNOWLEDGMENTS}

The author would like to express his sincere apprectation to $\mathrm{Mr}$. H.F. Butze of the NASA Lewts Research Center for his assistance in obtaining the experimental data.

\section{REFERENCES}

1. Lipfert, F.W., "Correlation of Gas Turbine Emissions Data," ASME Gas Turbine and Fluids Engineering Conference, San Francisco, Ca1., March 1972.

2. Rubins, P.M. and Marchtonna, N.R., "Evauation of $\mathrm{NO}_{\mathrm{x}}$ Prediction Correlation Equations for Smal1 Gas Turbines," AIAA/SAE 12th Propulsion Conference, Palo Alto, Cal., July 1976.
3. Marzesk1, J.M. and Blazowsk1, W.S., "Ambtent Temperature and Pressure Corrections for Aircraft Gas Turbine Idle Pollutant Emissions," ASME Gas Turbine and Fluids Eng'g. Conf., New Orleans, La., March 1976.

4. Sarl1, V.J., E1ler, D.C., and Marshall, R.I., "Effects of Operating Varfables on Gaseous Enissions," APCA Conf. on Alr Pollution Measurement Accuracy, New Orleans, La., Oct. 1975.

5. Nelson, A.W., Davis, J.C., and Medlin, C.H., "Progress in Techniques for Measurement of Gas Turbine Engine Exhaust Emisstons," AIAA/SAE 8th Propulsion Conference, New Orleans, La., Nov. 1972.

6. Mosier, S.A. and Roberts, R., "Low Power Turbopropulsion Combustor Exhaust Emissions," Technical Report AFAPL-TR-73-36, Vol. 3, July 1973.

7. Allen, L. and Slusher, G.R., "Ambient Temperature and Humidtty Correction Factors for Exhaust Emissions from Two Classes of Aircraft Turbine Engines," FAA-RD-76-149, Oct. 1976.

8. Fear, J.S., "Performance of a Smal1 Annular Turbojet Combustor Designed for Low Cost," NASA TM X-2476, 1972.

9. Anonymous, "Procedure for the Continuous Sampling and Measurements of Gaseous Emissions from Alrcraft Gas Turbine EngInes," SAE ARP 1256,1971 .

10. Roberts, R., Ftorentino, A.J., and Greene, W., Pollution Technology Program Can-Annular Combustor Englnes Final Report," NASA CR-135027, 1976.

11. Blazowsk1, W.S., Walsh, D.E., and Mach, K.D., "Prediction of Aircraft Gas Turbine NOx Emisston Dependence on Engine Operating Parameters and Ambient Conditions," AIAA/SAE 9th Propu1sion Conference, Las Vegas, Nevada, Nov. 1973.

12. Morr, A.R., Heywood, J.G., and Fitch, A.H., "Measurements and Predictions of Carbon Monoxide Emisstons from an Industrial Gas Turbine," Combustion Sclence and Technology, 11, 97, 1975.

13. Marchionna, N., Watkins, S., and Opdyke, Jr., "Turbine Fuel Tolerance Study," Avco J,ycoming TR 12090, Oct. 1975 .

14. Gordon, S. and McBride, B.J, "Computer Program for Calculation of Complex Chemical Equilibrium Compositions, Rocket Performance, Incident and Reflected Shocks and ChapmanJouguet Detonations," NASA SP-273, 1971.

15. Ay, J.H, and Stchel, M., "Theoretical Analysis of No Formation Near the Primary Reaction Zone in Methane Combustion, "Combustion and Flame, 26, 1, 1976.

16. Kollrack, R., "Mode1 Calculations of the Combustion Product Distributions in the Prinary Zone of a Gas Turbine Combustor," ASME Winter Annual Mtg., New York, 1976. 
17. Bittker, D.A, and Scullin, V.D., "Genera1 ChemIcal Kinetics Computer Program for Static and Flow Reactions, with Application to Combustion and Shock Tube Kinetics," NASA TN D-6586, 1972.

18. Muller-Dethlefs, K. and Sch1ader, A.F., "The Effect of Steatn on Flame Temperature, Burning Velocity, and Carbon Formation in Hydrocarbon Flames," Combustion and Flame, 27, 205, 1976.

19. Miles, G.A., Detroit Diesel Allison Division, personal communication, Aug. 1976.

TABLE I. IDLE JT8D-17 COMBUSTOR CONDITIONS

Nominal Operation ${ }^{10}$

$\begin{array}{ll}\text { Total Inlet Pressure } & 2.47 \mathrm{~atm} \\ \text { Total Inlet Temperature } & 393 \mathrm{~K} \\ \text { Air Flow } & 1.37 \mathrm{~kg} / \mathrm{sec} \\ \text { Fuel Flow } & 0.0161 \mathrm{~kg} / \mathrm{sec} \\ \text { Fuel/Air Rat lo } & 0.0117\end{array}$

Test Operation

$\begin{array}{lc}\begin{array}{l}\text { Compressor Efficiency } \\ \text { Compressor Pressure } \\ \text { Ratio }\end{array} & 0.8 \\ \begin{array}{c}\text { Compressor Inlet } \\ \text { Pressure }\end{array} & 2,3,4,5 \\ \begin{array}{l}\text { Compressor Inlet } \\ \quad \text { Temperature }\end{array} & \mathrm{I} \text { atm } \\ \begin{array}{c}\text { Compressor Inlet } \\ \quad \text { Re1ative Humidity }\end{array} & 244,289,322 \mathrm{~K} \\ \begin{array}{c}\text { Fue1/Air Ratio } \\ \text { Constant Compressor } \\ \text { Discharge Mach } \\ \text { Number }\end{array} & 0,50,100 \% \\ \begin{array}{c}\text { Constant Reference } \\ \text { Velocity }\end{array} & \mathrm{M}_{3}=0.007,0.011,0.015 \\ \end{array}$

TABLE II. COEFFICIENTS OF REGRESSION ANALYSIS

\begin{tabular}{lccc}
$\begin{array}{l}\text { Emission } \\
\text { Index } \\
\text { Coeff. }\end{array}$ & $\mathrm{HC}$ & $\mathrm{CO}$ & $\mathrm{NO}$ \\
$\begin{array}{c}\text { All Data } \\
\text { a }\end{array}$ & -1.2833 & -0.9468 & 0.2547 \\
$\mathrm{~b}$ & 15.806 & 11.552 & -2.916 \\
$\mathrm{c}$ & -0.00400 & -0.00981 & 0.02074 \\
$\mathrm{~d}$ & -128.93 & -243.48 & 324.67 \\
$\mathrm{e}$ & 43.30 & 76.39 & -59.88 \\
Multiple Cor- & .934 & .929 & .824 \\
relation Coef. & & & \\
Squared & & & \\
Selected Data & & & \\
\hline a & -1.9130 & -1.1214 & 0.2552 \\
b & 20.135 & 13.411 & -2.090 \\
c & -0.00341 & -0.00763 & 0.0 \\
d & -107.35 & -196.11 & 334.44 \\
e & 34.61 & 77.04 & -54.31 \\
Multiple Cor- & .953 & .940 & .955 \\
relation Coef. & & & \\
Squared & & &
\end{tabular}

TABLE III. KINETIC SCHEME OF METHANE/AIR COMBUSTION AND FORWARD RATE CONSTANTS

$$
\mathrm{k}_{\mathrm{f}}=\mathrm{AT}^{\alpha} \mathrm{e}^{-\Delta \mathrm{E} / \mathrm{RT}}\left(\mathrm{cm}^{3} / \mathrm{mole} / \mathrm{sec}\right)
$$

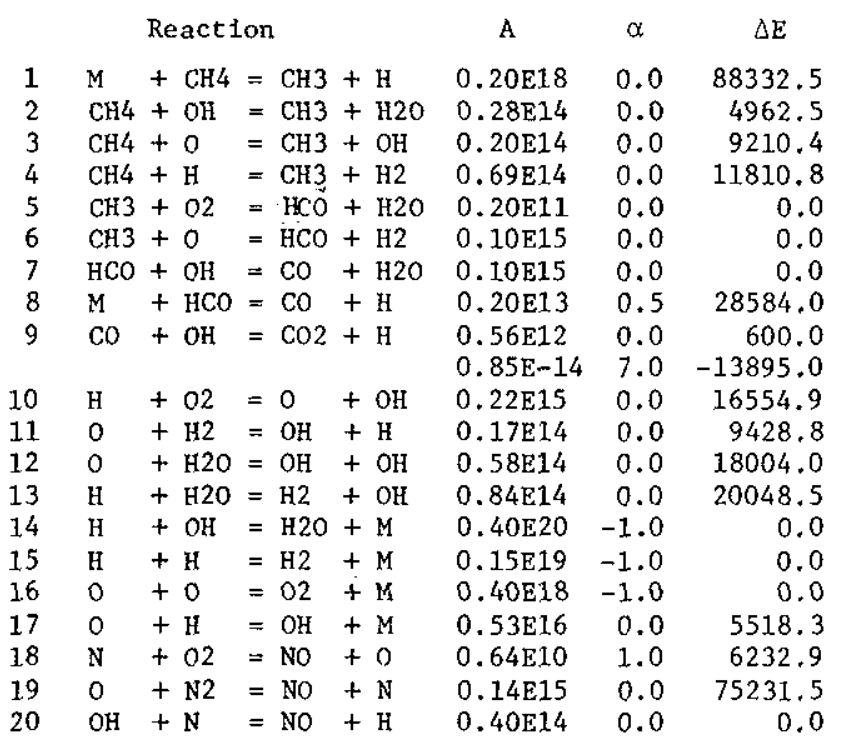

TABLE IV. TYPICAL LOCAL FUEL/AIR RATIOS AND AVERAGE RESIDENCE TIMES

\begin{tabular}{lllllll} 
& \multicolumn{2}{c}{ Primary } & \multicolumn{2}{c}{ Secondary } & \multicolumn{2}{c}{ Dilution } \\
& High & Low & High & Low & High & Low \\
f/a & 0.071 & 0.048 & 0.034 & 0.019 & 0.012 & 0.011 \\
$\tau$ (ms) & 1.90 & 1.60 & 4.47 & 3.54 & 2.62 & 2.45
\end{tabular}

TABLE V. HYDROCARBON EMTSSIONS

Ambient Correlations Hydrocarbon Emission Index Static Convective Experi-

$\begin{array}{lllll}322 \mathrm{~K}, & 0 \% \mathrm{RH} & 1.5 & 1.5 & 1.5\end{array}$

$\begin{array}{lllll}244 \mathrm{~K}, & 0 \% \mathrm{RH} & 3.19 & 2.59 & 14.4\end{array}$

$322 \mathrm{~K}, 100 \% \mathrm{RH} \quad 4.35 \quad 3.48 \quad 17.6$ 


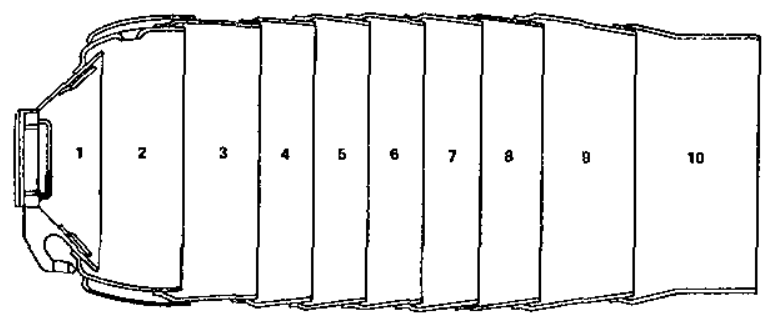

FUEL INJECTOR AND PRIMARY SWIRLER EQUIVALEN'? METERING AREA 7.618

Equivalent Metering Area

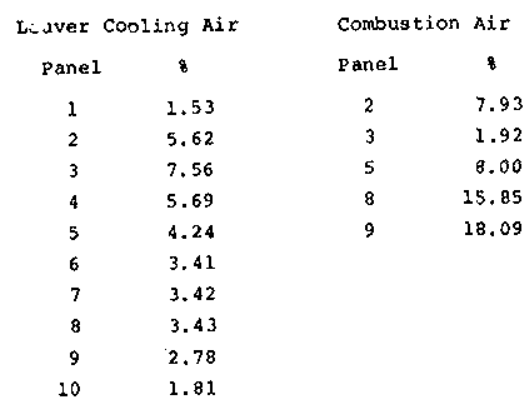

FIGURE 1. JT8D-17 COMBUSTOR

$\triangle$ STATIC PRESSURE

- TOTAL TEMPERATURE

- GAS SAMPLE PROBE

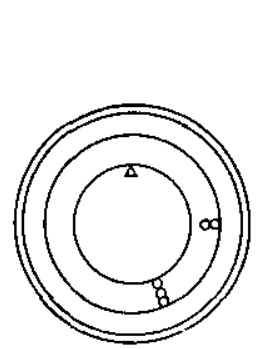

SECTION A-A

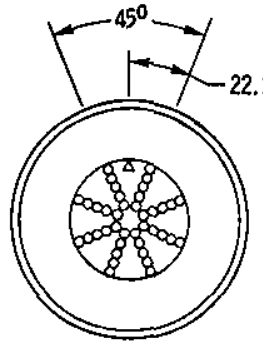

SECTION B-B

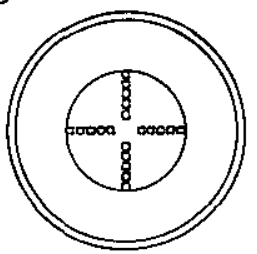

SECTION C-C COMBUSTOR INLET THERMOCOUPLE LOCATION GAS SAMPLE PROBE LOCATION

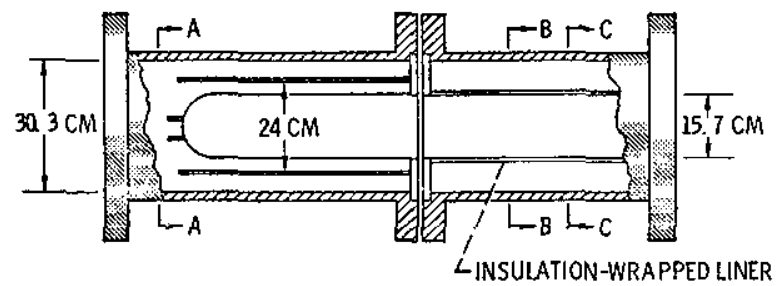

FIGLRE 2. COMBUSTOR ASSEMBLY AIID IISTTRUMEITATIOII SECTLOHS

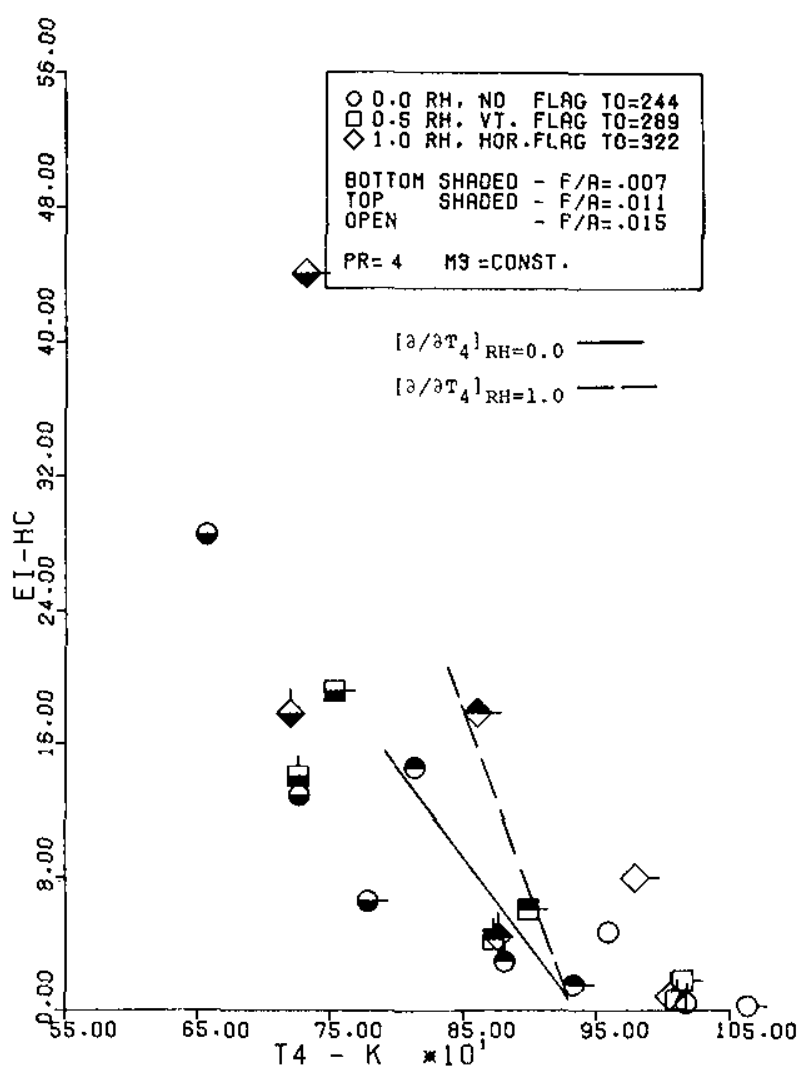

FIGURE 3. HYDROCARBON EMISSION INDEX, JTRD-17

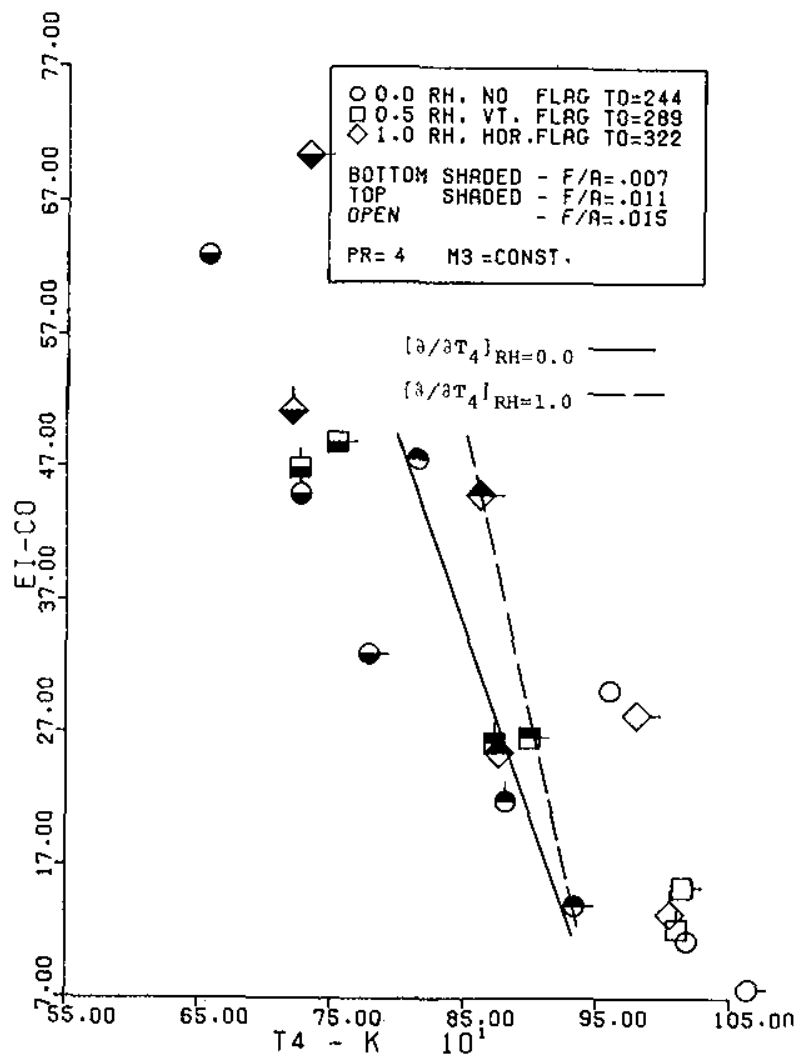

FIGURE 4. CARBOH MONOXIDE EMISSION INDEX, JT8D-17 

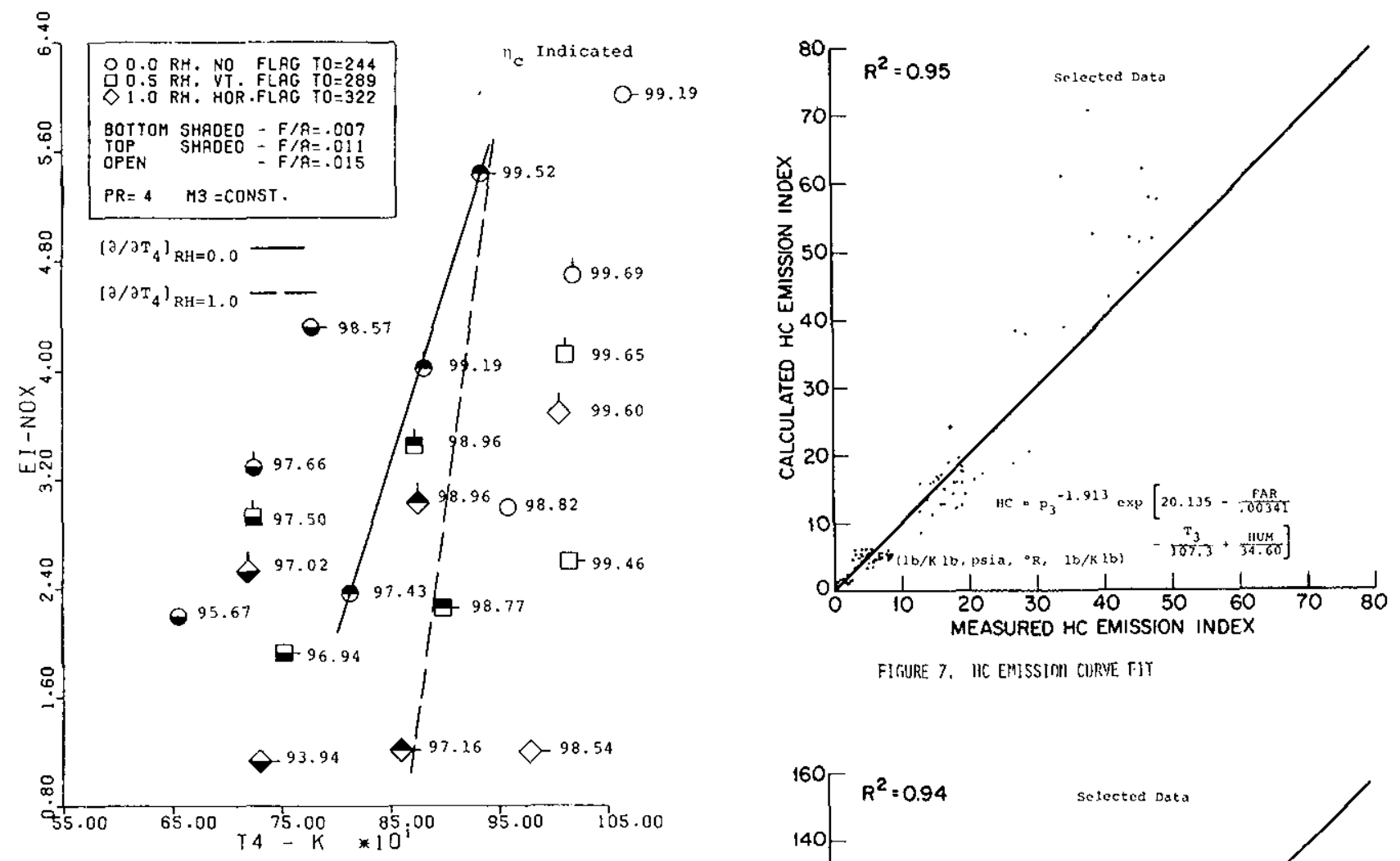

FIGURE 7, HC EMISSION CORYE FIT

FIGURE 5, OXIDES OF :ITTROGEN EMISSION IHDEX, JT8D-17
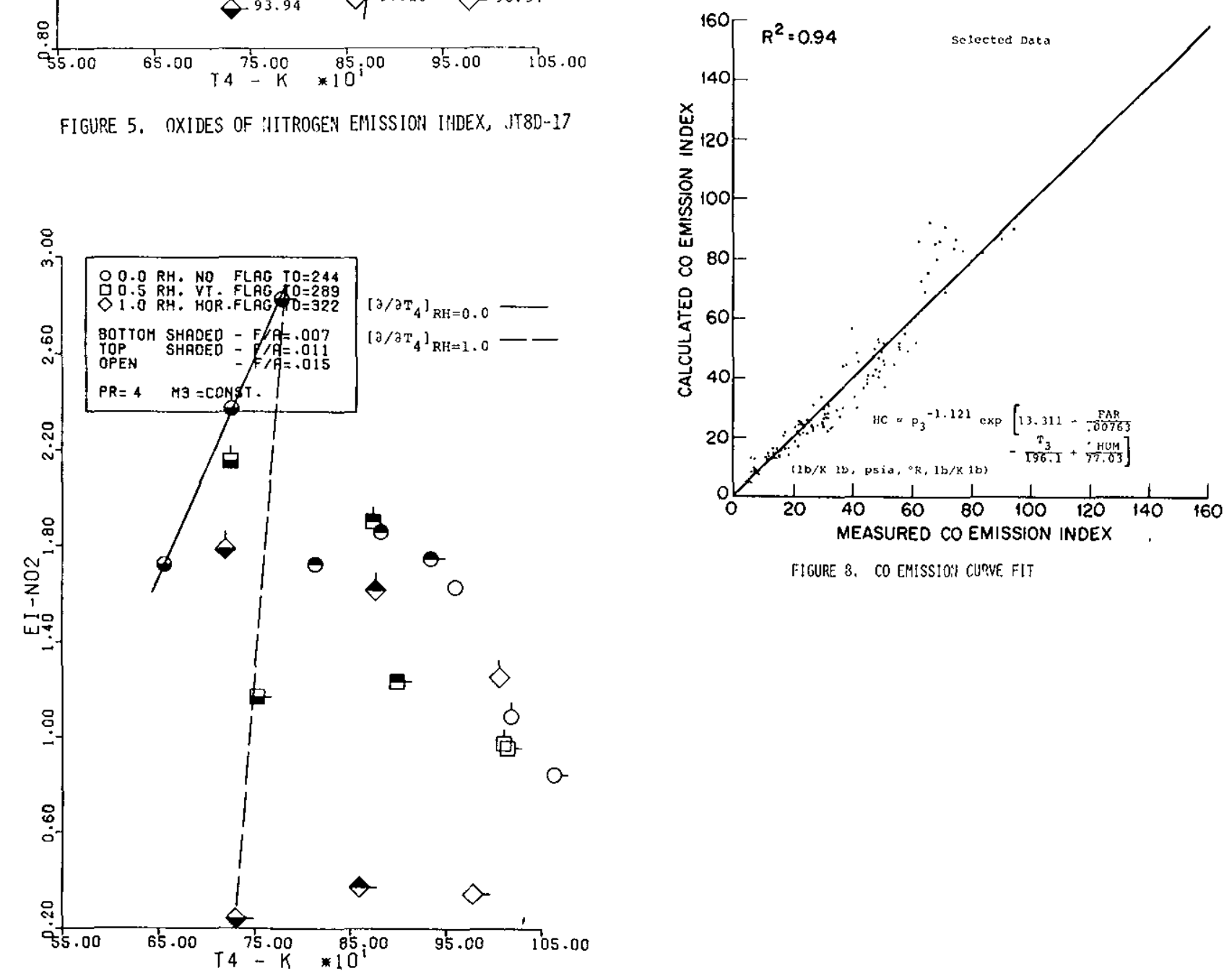

F!GURE 3, CO EMISSI0: CUPVE, FIT

FIGURE 6. IITROGEN DIOXIDE EMISSION INDEX, JT8D-17 

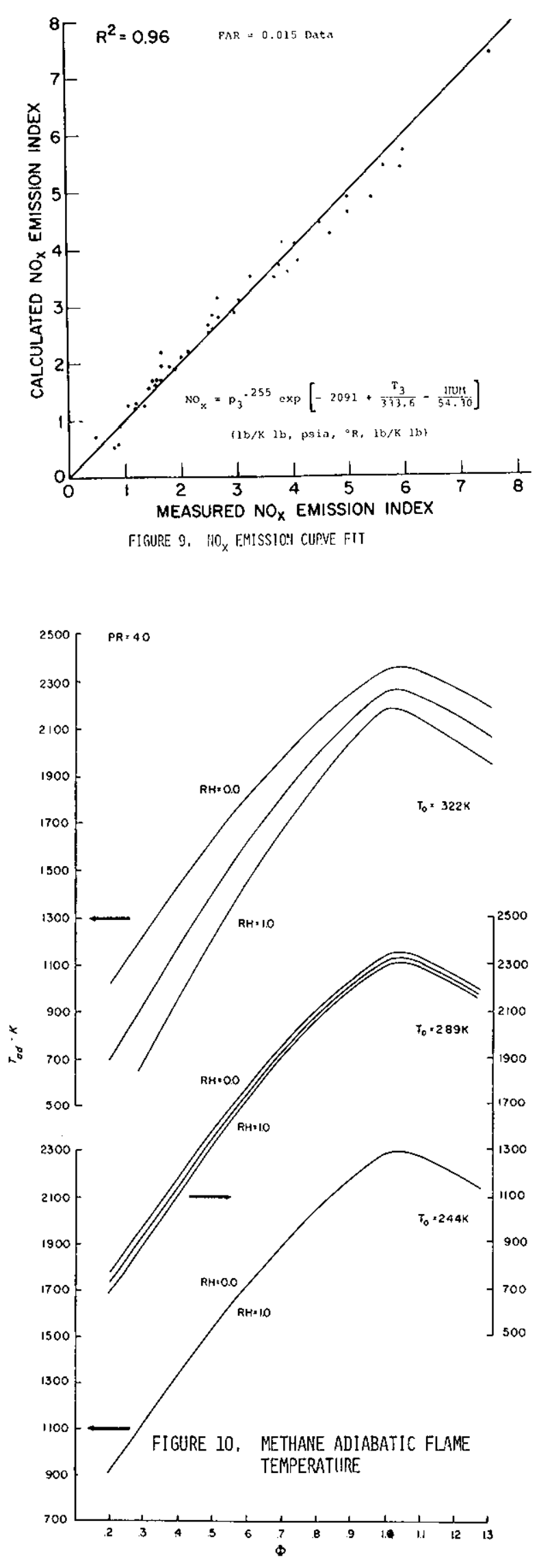

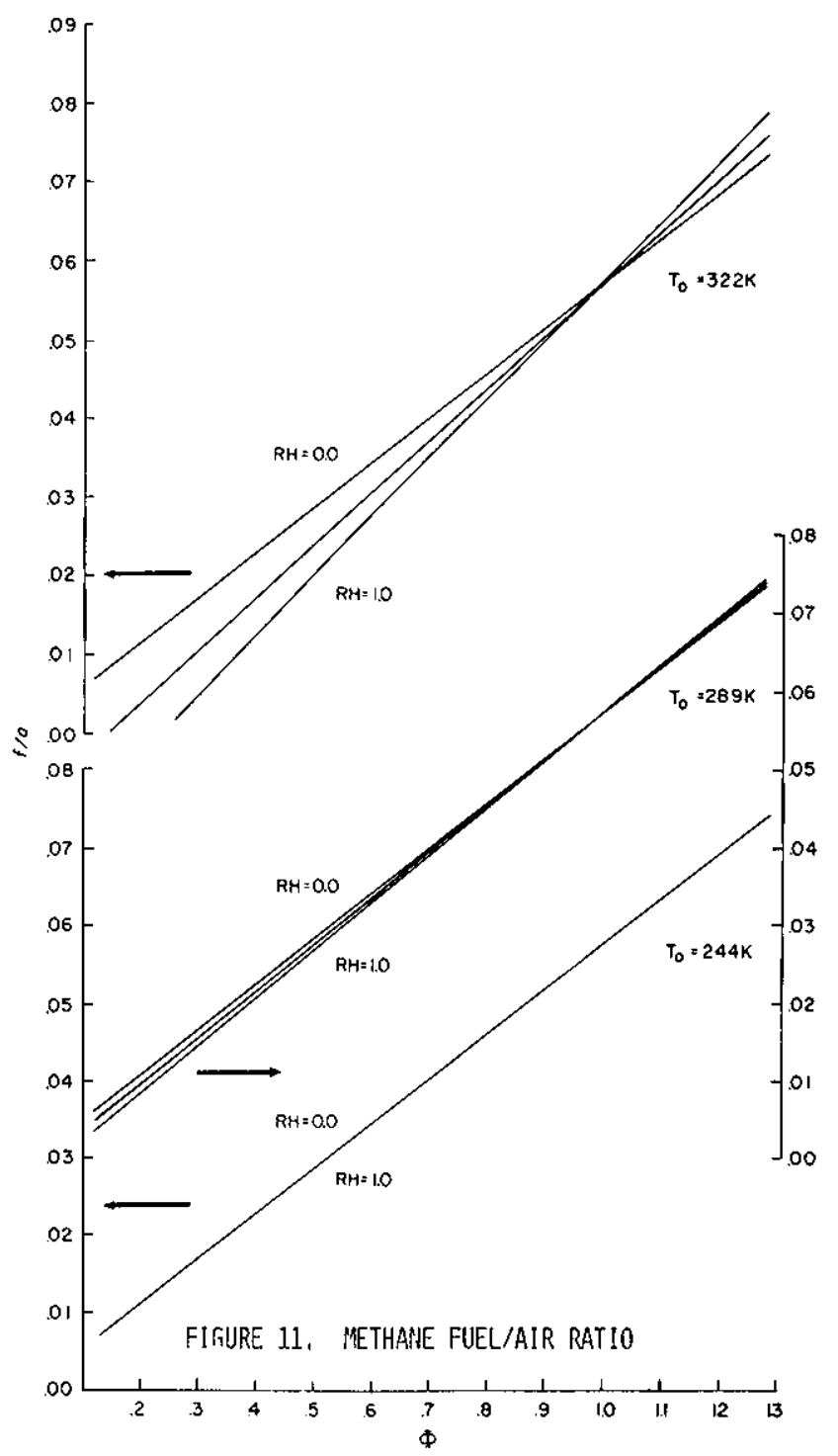



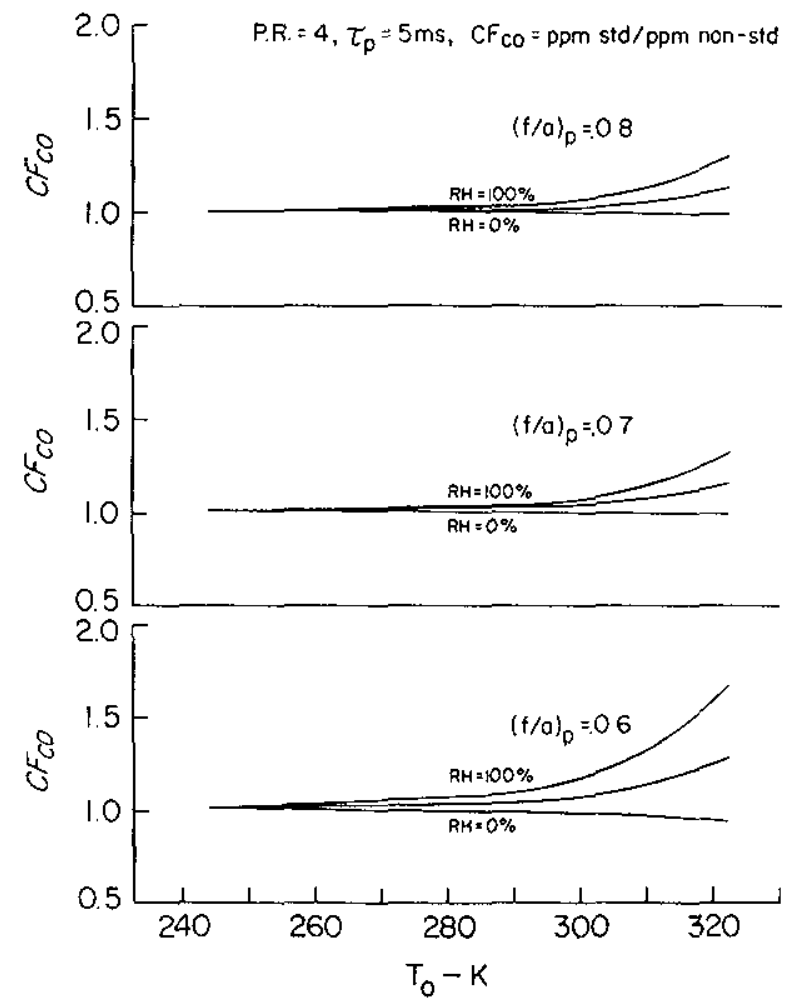

FIGUPE 12. NORMALIZED PRIMARY ZDNE CARBOH MENOXIDE EMISSIOHS, METHANE KIHETIC SCHENE

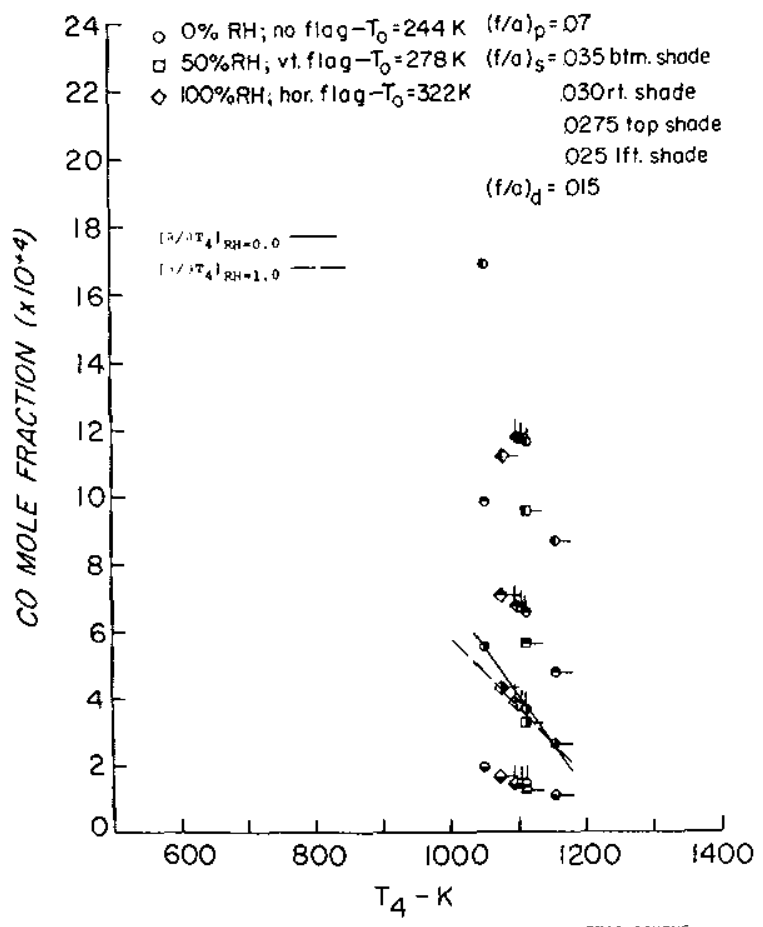

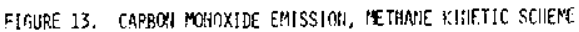

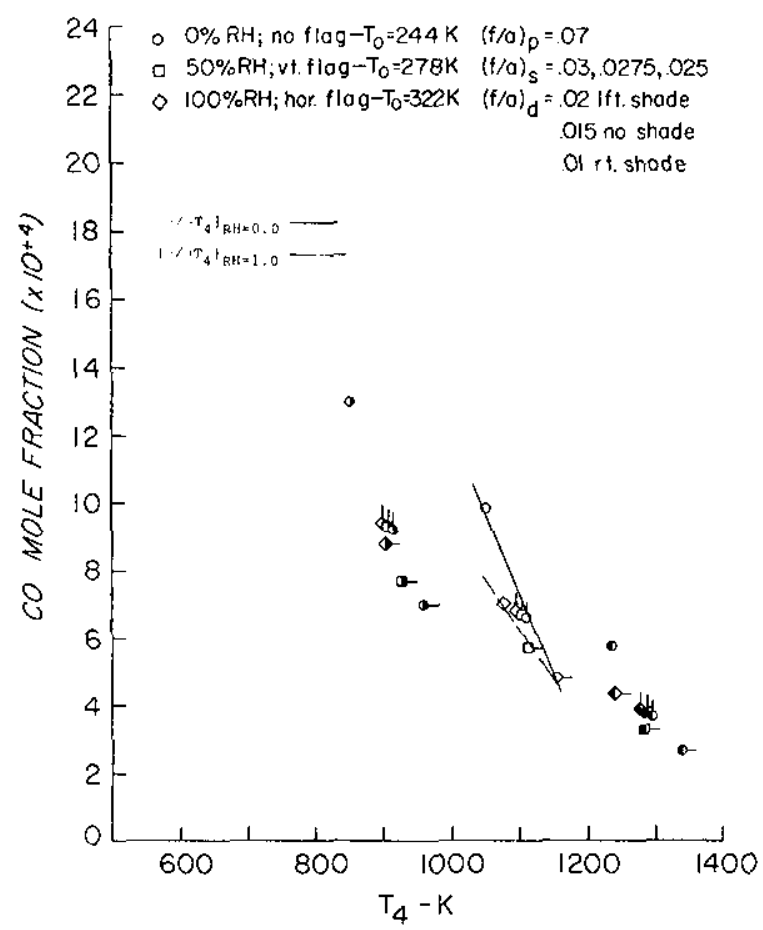

FIFIIPE. 14. CARRON MOROXIDE EMISSIMW, METHANE KINETIC SCHEME

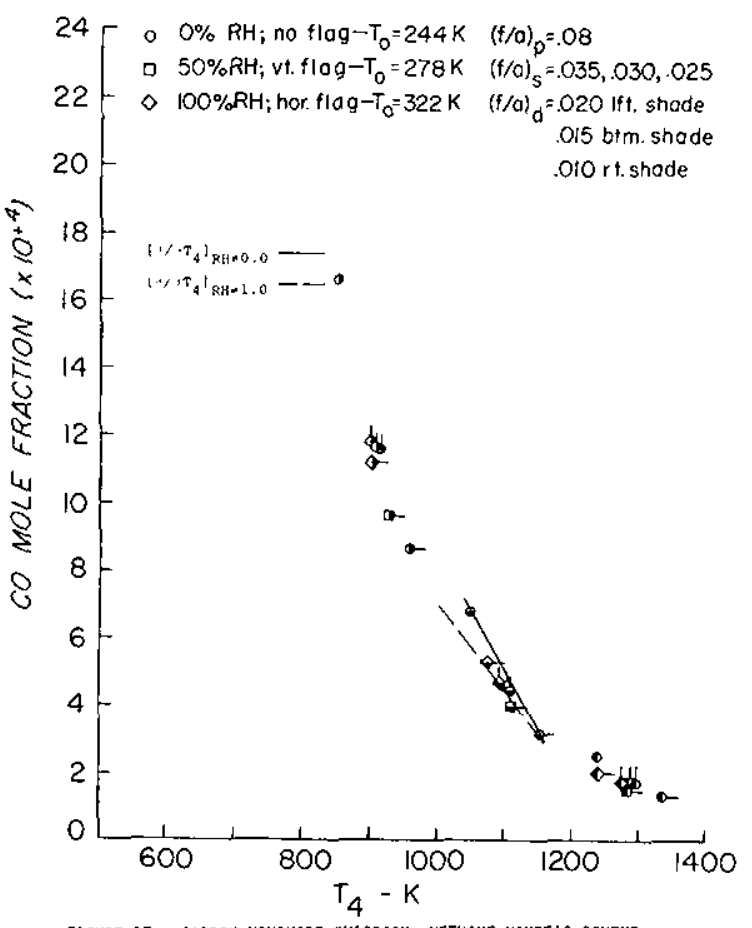

FIGURE 15, CARBNA MONOXIDE EMISSION, METHANE KIHETIC SCHEME 


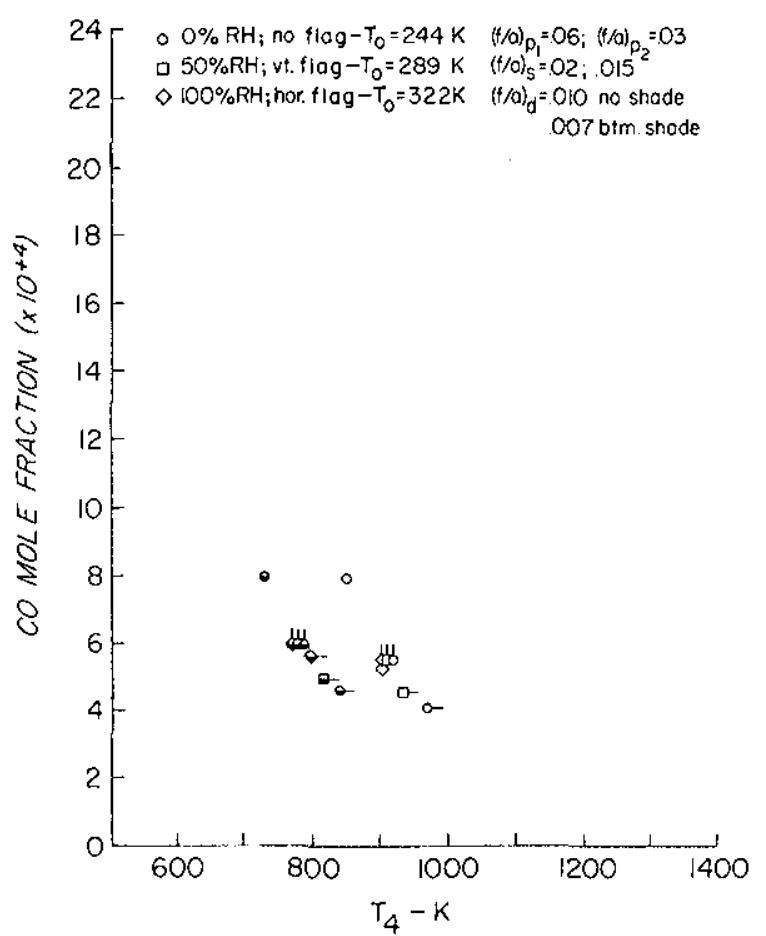

FIGUPF 16, CARBON MOMOXIDE EMISSIDAS, METHANE KTHETIC SCHEME

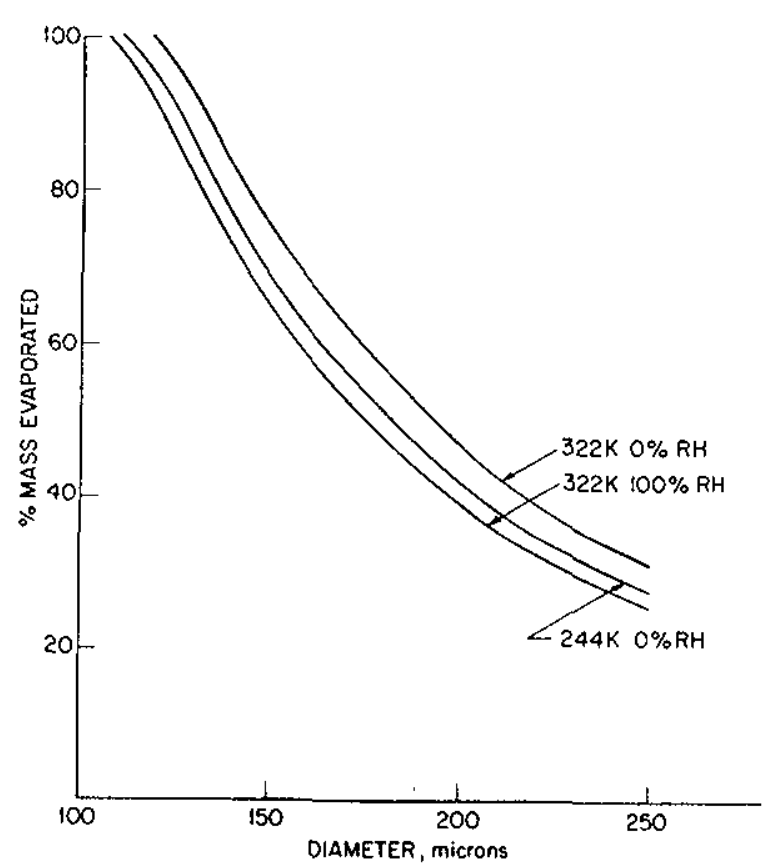

FIGURE 17, FUEL DROP EVAPORATIO:

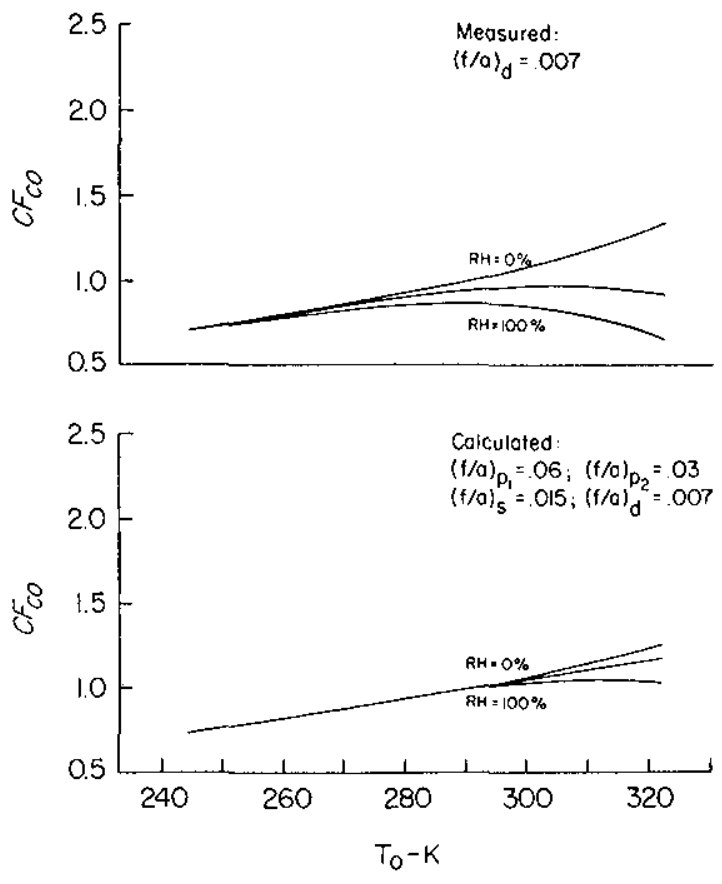

FIGURE 18. AMBIENT TEMPERATURE AHS HUMINTYY CORRECIION FACTORS, .1780-17
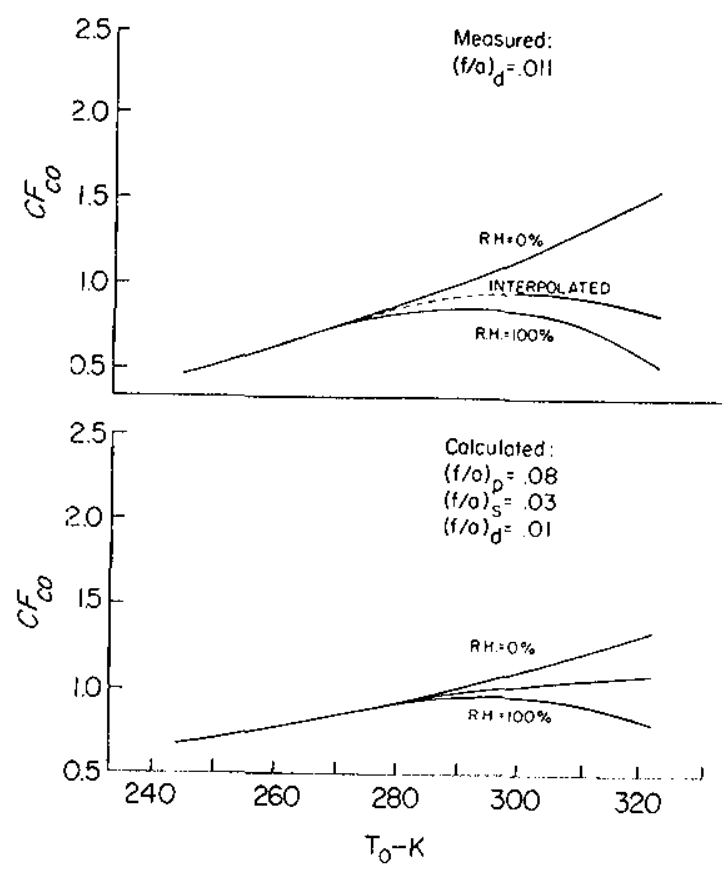

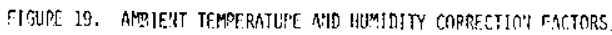
$.73 n-17$ 

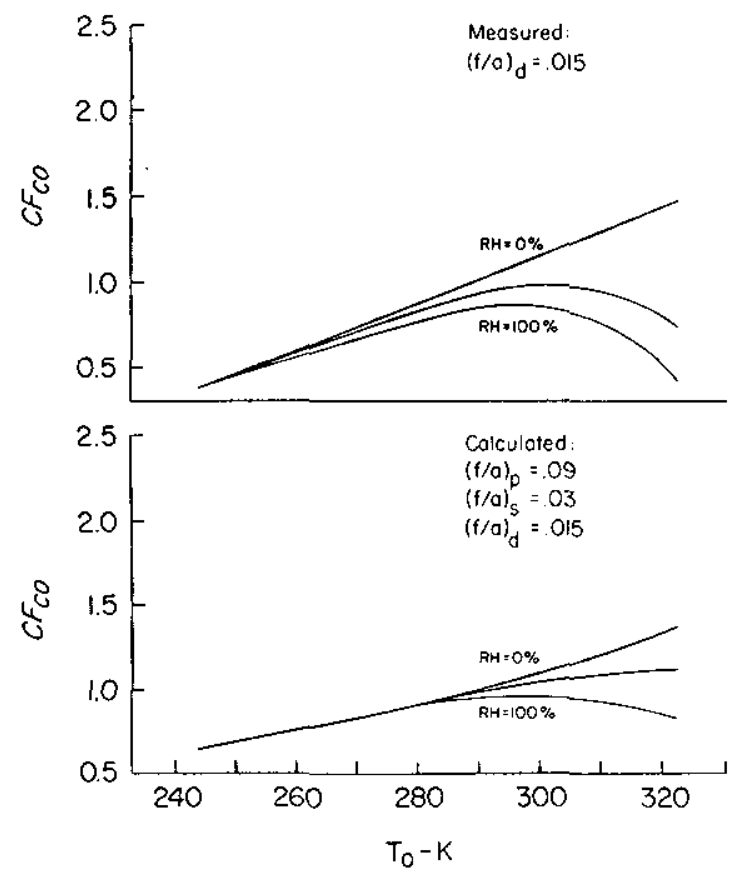

FIGURE 20. RNBIEHT TEMPERATHRE AIBD HUMIDITY CORRECTIOI FACYORS, ITRB-17

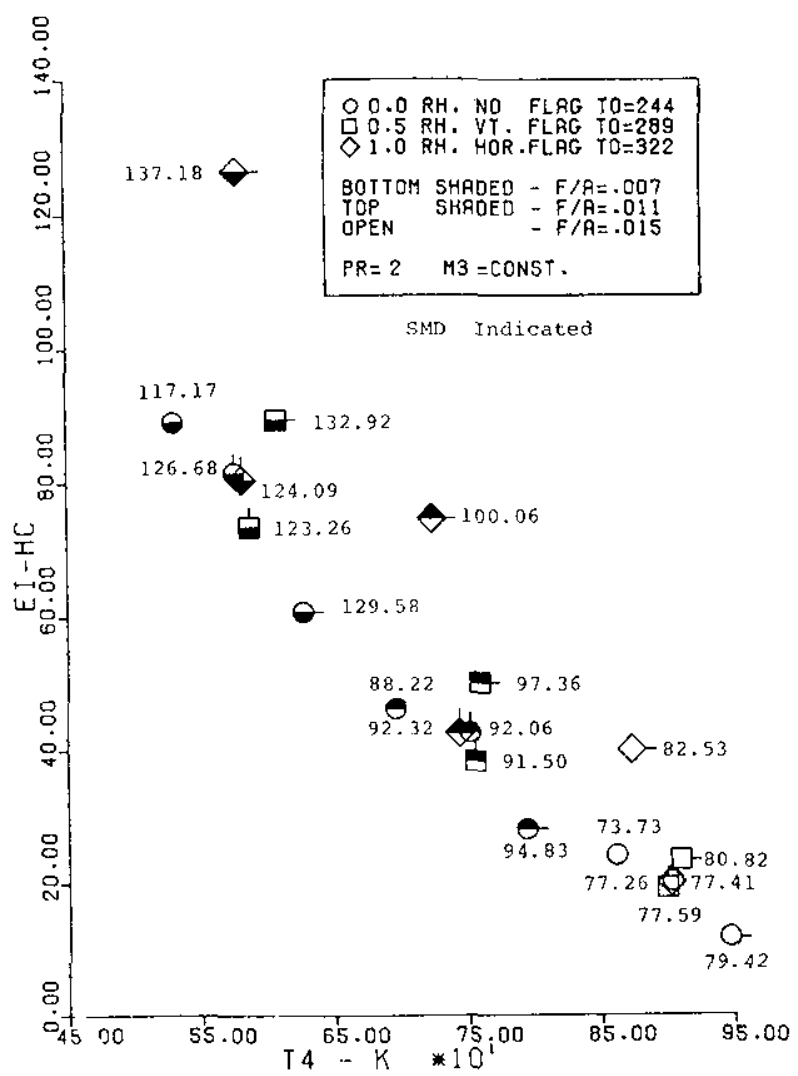

FIGURE 21. HYDROCARBON EMISSIONS, SMD EFFECT 